\title{
Using a Mathematical Model of Motivation, Volition, and Performance to Examine Students’ E-Text Learning Experiences
}

\section{Elena Novak ${ }^{1}$, Jerry Daday ${ }^{2}$, and Kerrie McDaniel ${ }^{2}$}

1Kent State University, School of Lifespan Development and Educational Sciences

Kent, OH 44242-0001, USA

Email: elannovak@gmail.com

2Western Kentucky University, Center for Faculty Development

Bowling Green, KY 44101, USA

This is the author's manuscript of the article published in final edited form as:

Novak, E., Daday, J., \& McDaniel, K. (2018). Using a mathematical model of motivation, volition, and performance to examine students' e-text learning experiences. Educational Technology Research and Development, 66(5), 1189-1209. https://doi.org/10.1007/s11423-018-9599-5 


\begin{abstract}
This empirical study used Keller's (2008b) Motivation, Volition, and Performance (MVP) theory to develop and statistically evaluate a mathematical MVP model that can serve as a research and policy tool for evaluating students' learning experiences in digital environments. Specifically, it explored undergraduate biology students' learning and attitudes toward e-texts using a MVP mathematical model in two different e-text environments. A data set $(N=1,334)$ that included student motivation and e-text information processing, frustration with using e-texts, and student ability variables was used to evaluate e-text satisfaction. A regression analysis of these variables revealed a significant model that explained $77 \%$ of the variation in student e-text satisfaction in both e-text learning environments. Student motivation and intrinsic cognitive load were positive predictors of student satisfaction, while extraneous cognitive load and student prior knowledge and background variables were negative predictors. Practical implications for e-text learning and generalizability of a mathematical MVP model are discussed.
\end{abstract}

Keywords: mathematical modeling; e-texts; learning; motivation; information processing 


\section{Introduction}

Electronic textbooks (e-texts) are gaining in popularity in K-12 and higher education settings. A growing number of education policy makers, researchers, and practitioners view digital textbooks as an integral part of the $21^{\text {st }}$ century education system and urge transitioning from printed materials to electronic texts (Apple, 2015; Fletcher, Schaffhauser, \& Levin, 2012). One of the major advantages of e-texts is their portability, giving students the ability to study anywhere and anytime using an electronic device connected to the Internet. Emerging e-text technologies provide interactive multimedia content allowing users to customize their e-text learning based on individual preferences and learning progress. This supports student motivation and their engagement with e-texts. These technological advances are believed to change the way students interact with and perceive books (Boroughs, 2010).

There are many psychological and environmental factors that influence student e-text learning experiences and satisfaction. Research on e-texts use and adoption in educational settings shows that overall students have positive attitudes toward electronic textbooks. Nevertheless, students do not show a strong preference for e-texts over printed materials (Shepperd, Grace, \& Koch, 2008; Woody, Daniel, \& Baker, 2010). For instance, many individuals report difficulty reading off a screen, understanding and comprehending complicated e-texts, and fatigue (Le Bigot \& Rouet, 2007; Rockinson- Szapkiw, Courduff, Carter, \& Bennett, 2013). They prefer printing certain e-text documents because it helps them better understand the materials and improve productivity (Woody, Daniel \& Baker, 2010). Some students even prefer to buy a more expensive printed textbook instead of a cheaper e-text alternative (Shepperd et al., 2008). In addition, undergraduate students perceive e-texts to be less interesting and credible than traditional print textbooks (Liu, 2005). 
Many researchers argue that reading on electronic platforms requires fundamentally different abilities and skills than reading a print textbook (Ackerman \& Lauterman, 2012; Lamb, 2001). Reading e-texts involves a whole set of new literacy practices, such as highlighting, bookmarking, digital note-taking, and configuring e-text settings. Many of these practices involve digital collaboration and document sharing, creating an additional layer of new literacy skills, which need to be taught (Hyman, Moser, \& Segala, 2014). Moreover, reading off a screen involves different reading behaviors than reading printed materials. People who read off a screen often employ non-linear or selective reading, scanning, keyword spotting, and browsing, which results in declined sustained attention (Liu, 2005).

Moreover, student e-text preferences can also vary based on the course requirements and are considerably influenced by instructor's use of the e-texts (Dennis, 2011; Weisberg, 2011). Thomas (2013) argues that students' e-textbook use closely mirrors instructor's use and expectations. Students tend to direct their attention toward e-textbook features and content that are emphasized by their teacher and underutilize many interactive and self-directed e-textbook components. Moreover, e-textbook use is not intuitive; students need to be taught how to use etextbooks effectively for their learning (Thomas, 2013).

Although several studies have examined student e-text learning and attitudes, the relationships among the psychological and environmental factors influencing e-text learning and satisfaction are unclear and underexplored. Thus, the intent of this study is to examine the relationships among psychological, environmental, and student ability variables that affect student satisfaction with e-text learning using Keller's (2008b) integrative theory of Motivation, Volition, and Performance (MVP) theory and to develop a mathematical MVP model that can quantitatively represent such relationships. 
The concept of satisfaction has been debated extensively in the literature from various perspectives, including a variety of intrinsic and extrinsic factors contributing to feelings of satisfaction, cognitive evaluation of a task and its outcomes, and strategies that promote satisfaction (Keller, 2010). Researchers believe that satisfaction is an important aspect of human performance, because feelings of satisfaction with the learning process or its outcomes contribute to a continuing desire to learn. The importance of satisfaction with IT systems has been extensively debated in the literature, as it directly influences individuals' attitude, intention, and continued desire to use a technology (Deng, Turner, Gehling, \& Prince, 2010; Kang \& Lee, 2010; Sepehr \& Head, 2017). In this study, we define satisfaction as a subjective evaluation of an actual experience or its outcome based on a learner's expectations (Keller, 2010). This definition is grounded in cognitive dissonance theory (Festinger, 1957), expectation confirmation theory (Oliver, 1977; 1980) and balance theory (Heider, 1958; Hummon \& Doreian, 2003) - all of which provide a rigorous foundation for research on the design of digital learning environments that promote a desire to learn.

\section{An Integrative Theory of Motivation, Volition, and Performance}

An integrative theory of motivation, volition, and performance (Keller, 2008b) takes a broad view of various factors that influence human performance and learning while synthesizing multiple theoretical approaches and explanatory frames of reference. Unlike single theories that examine isolated constructs, integrative theories offer a broader framework that focuses on interactions of different theories and a basis for comprehensive and cross-paradigm research. Keller's (2008b) integrative theory of motivation, volition, and performance (MVP) focuses on the learning, motivational, volitional, psychological, and environmental factors that affect human performance. This theory can be characterized as a macro theory that incorporates various micro 
theories, including information-processing theories (Atkinson \& Schiffrin, 1971; Mayer, 2001), motivation (Keller, 1999), action control theory (Kuhl, 1987), self-regulation (Zimmerman, 2001), and implementation intentions (Gollwitzer, 1999).

Using a systems model approach, Keller developed a MVP model to systematically represent relationships among explanatory components of the MVP theory (Figure 1). The MVP model describes inputs (i.e., considered to play an important role in explaining the theoretical principle), interactions among them, and outputs (i.e., measurable behaviors to be explained). The MVP model emphasizes two major types of inputs that affect individual motivation and performance: environmental factors and psychological constructs. Environmental, or external inputs, represent a myriad of cultural, social, and physical factors, including quality of instruction and/or learning materials, technical support in digital learning environments, and teacher enthusiasm, and may directly affect student learning and motivation. For example, Sun, Tsai, Finger, Chen, and Yeh (2008) found that teacher attitudes toward e-Learning as well as eLearning course structure, perceived usefulness, and assessment strategies can considerably influence student e-Learning satisfaction. 


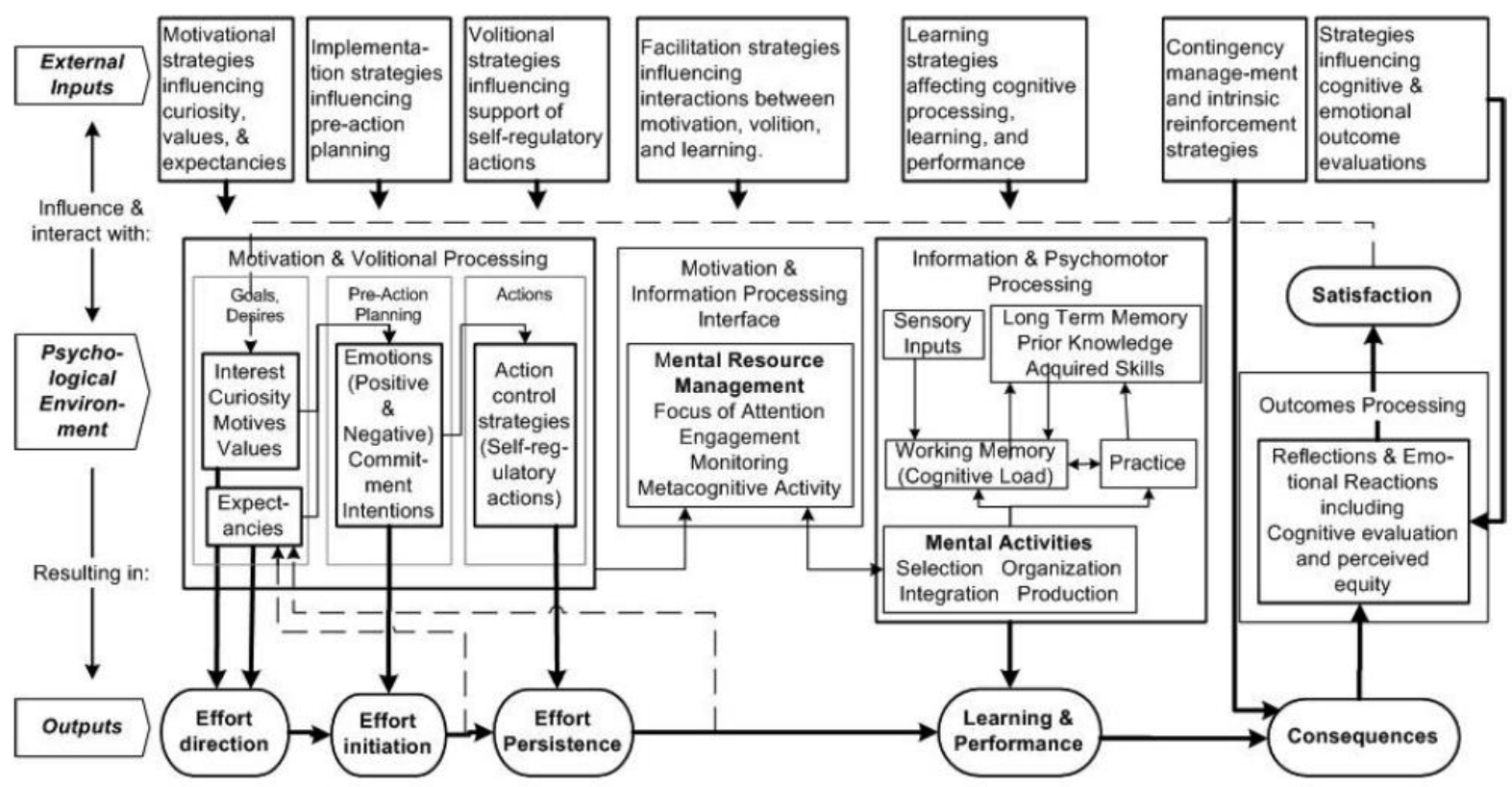

Figure 1. The MVP model of motivation, volition, and performance according to Keller (2008a).

Note. Reprinted with the permission of John Keller from "An Integrative Theory of Motivation, Volition, and Performance,” by J. Keller, 2008, Technology, Instruction, Cognition and Learning, 16, 79-104, p. 94.

Psychological constructs, or internal processes, include factors, such as motivation, selfregulation control, and information processing. For instance, cognitive load experienced during the learning process can directly affect student performance levels and satisfaction with the learning process (Paas, Renkl, \& Sweller, 2003). This is particularly relevant when learning complex cognitive skills in digital learning environments that offer an additional layer of multimedia and interactivity when compared to paper-based or lecture situations. Information processing in multimedia learning is another relevant concept that influences human performance and satisfaction. Mayer's (2001) research on learning with multimedia supports the importance of implementing multimedia learning principles for designing effective and efficient 
learning materials that utilize pictures and words. The MVP model helps understand the interactive influences of the external and internal processes and their effect on human learning and performance, which will be also affected by individual ability, prior knowledge, and skills.

The MVP model's output variables focus on individual effort direction, effort initiation, effort persistence, and outcomes processing. These output variables represent the "processes that occur in moving from initial motivation to sustained effort" (Keller, 2008b, p. 88). The "outcome processing" stage covers post-actional motivational processes, such as self-evaluation of achievement levels and reflection on the learning processes. These post-actional motivational behaviors determine individual's satisfaction with the involved outcomes and processes.

Satisfaction is also viewed as an output variable in the MVP model, as it is clearly influenced by various environmental, psychological, sociological, and genetic factors coupled with the student's performance and the student's mental evaluation of his/her archived performance, which is based on the gap between his/her current and desired performance levels. Satisfaction with the learning outcomes and processes is also one of the four components of the ARCS model of motivation that describes motivational dimensions of learning and performance (Keller, 1999): (1) Attention (i.e., interest or curiosity), (2) Relevance (i.e., goals or motives), (3)

Confidence (i.e., expectancy for success), and (4) Satisfaction (with the learning process). Keller views the first three ARCS components, attention, relevance, and confidence, as the MVP model's internal psychological factors (i.e., inputs) that represent learning conditions. The fourth ARCS component, satisfaction, represents a learning processing outcome (see Figure 1).

\section{A Mathematical MVP Model}

A mathematical model, or any model in general, represents reality in a simplified form. According to Pearl (2000, p. 202), a model is "an idealized representation of reality that 
highlights some aspects and ignores others." A mathematical model can be described using a mathematical equation or a series of mathematical equations that represent relationships among quantitative variables. The goal of mathematical model building is to develop a model that would provide an accurate, yet relatively simple representation of reality. Mathematical models are widely used in science to explain natural phenomenon and make predictions (Pfaffl, 2001; Tamura, Masatoshi, \& Sudhir, 2004). Behavioral researchers develop mathematical models to represent descriptive theories using mathematical concepts (Boland, 2014). One of the key advantages of developing mathematical models that explain theories is to test theoretical claims and evaluate the extent to which the models match empirical data collected in order to examine a particular area of inquiry (Rodgers, 2010).

The reason for selecting Keller's (2008b) integrative MVP theory as a theoretical framework for the present study was twofold. First, since the goal of the study was to develop a mathematical model that represents relationships among various variables that affect students' etext learning experiences it was important to select a rigorous, well-established theory that lends itself to mathematical modeling. Keller's MVP theory was a perfect candidate for this task due to the (1) integrative nature of the theory, which allows for an exploration of a myriad of environmental and psychological factors that affect students' learning experiences, and (2) systems model approach that represents relationships among MVP theory components. To highlight the difference between the MVP theory and MVP model, Keller (2008a) wrote, "The phrase MVP model refers to this systems representation [that shows how all of the parts are interrelated and illustrates relationships that occur as explained and predicted by the theory] while MVP theory refers to the explanatory structures represented by the components of the theory" (p. 81). 
Second, the present study builds upon previous research on mathematical models of MVP. The MVP theoretical framework was successfully used to develop a mathematical MVP model to evaluate human performance in several digital learning environments, including video games (Huang, Huang, \& Tschopp, 2010) and simulations (Author, 2014). Both studies found empirical support for the elements included in the MVP theory and revealed statistically significant relationships among motivational, volitional, and learning outcome processing variables. The mathematical model revealed in these studies can be captured using the following linear equation (Equation 1):

Satisfaction (student) $=\mathrm{A} \times$ Attention (student $)+\mathrm{B} \times$ Relevance $($ student $)+\mathrm{C} \times$

$$
\text { Confidence (student) }+\mathrm{D} \times \text { Volition (student) }
$$

(A, B, C, and D are positive parameters).

This mathematical MVP model represents the relationships among individual internal processes (i.e., motivation and volition) and learning outcome processing (i.e., satisfaction) and was statistically evaluated for fitting two different data sets collected to assess student performance in video games (Huang et al., 2010) and simulations (Author, 2014). Both studies confirmed that attention, relevance, confidence, and volitional effort were significant and effective positive predictors of student's satisfaction with the experienced learning processes, thus providing empirical support for these MVP theory elements. The present study aims to further demonstrate the generalizability of this mathematical model by testing for additional empirical support of these MVP elements. These MVP elements will be used to develop a more comprehensive mathematical MVP model that can be applied to other digital learning 
environments as a means of diagnosing students' learning experiences. Specifically, the goal is to (1) statistically evaluate this mathematical model (Equation 1) for fitting two different data sets collected to assess undergraduate biology students' e-text satisfaction and attitudes, and (2) expand this model by including additional variables that affect student outcome processing in etext learning environments, and (3) determine whether the expanded model fits the empirical data. Furthermore, this report draws practical recommendations for e-texts learning from the MVP model and discusses the generalizability of the MVP mathematical model across different digital learning environments.

In addition to the MVP theory variables explored in previous studies (i.e., motivation, volition, and learning outcome processing), the current study included indicators of (a) student information processing in e-text learning environments, (b) environmental factors (frustration with using e-texts), and (c) student ability variables (prior knowledge and academic background). Information processing was measured using a Likert-type e-text cognitive load instrument that assessed e-text intrinsic and extraneous cognitive load (Authors, 2018). The concepts of intrinsic and extraneous load (Leppink, Paas, Van der Vleuten, Van Gog, \& Van Merriënboer, 2013; Leppink, Paas, van Gog, van der Vleuten, \& van Merriënboer, 2014) relate to general information processing and are essential to the MVP theory (Keller, 2008b). Intrinsic cognitive load (IL) is influenced by student prior knowledge and learning task difficulty, whereas extraneous cognitive load (EL) involves processes that do not contribute to knowledge construction and may even hamper the learning process. Research shows that IL and EL play an important role in student learning and satisfaction and therefore these variable were considered in the development of a mathematical MVP model. 
The influence of environmental factors related to e-text instructional alignment and technical issues was assessed using a Likert-type questionnaire that evaluated student frustration with these factors. Frustration with computers and web browsing is a well-known universal experience for digital media consumers (Ceaparu, Lazar, Bessiere, Robinson, \& Shneiderman, 2004). Keller (2008b) suggested that frustration with the environmental conditions (external inputs), such as technology and computers, is one of the areas of inquiry that is directly related to the MVP model: "User efforts to perform well... are frustrated by the environmental conditions (external inputs) that either facilitate or restrict performance due to poor man-machine interfaces” (p. 97). In a similar vein, a lack of instructional alignment between e-textbooks and course goals and requirements can lead to frustration with using e-text materials, directly influencing a student's satisfaction (Keller, 2008a; Wigfield \& Eccles, 2000).

In the current study, student ability variables included student prior knowledge as measured by their college admissions test (ACT math scores) and their academic background as measured using the number of completed academic hours at the time of data collection. ACT math performance is considered a good predictor of student success in undergraduate biology courses since it measures mathematical aptitude and reasoning skills that are critical indicators of achievement in college biology (Anderson, 2014; Biermann \& Sarinsky, 1989). Student prior knowledge and academic experience can influence a student's e-text satisfaction directly interacting with environmental and psychological factors. These ability variables affect student academic engagement and attitudes toward learning and, therefore, can influence a student's mental evaluation of the entire learning process. 


\section{Method}

\subsection{Participants}

A total of 2,392 undergraduate biology students at a four-year public comprehensive university located in the southeastern United States were invited to participate in the study. Out of 2,392 students, 1,334 consented to participate in the study (55.8\% participation rate). However, only 727 students completed all of the study questionnaires. Students were enrolled in six general biology courses $(N=456)$ and two anatomy and physiology $(\mathrm{A} \& \mathrm{P})$ laboratory courses $(N=271)$. Among all participants, $63 \%$ were female, $17 \%$ represented a racial/ethnic minority group, the average age was 20.4 years old, and the average student had completed 56 credit hours of course at the time of the study. Moreover, $75.9 \%$ of the participants had used etexts in previous classes, and $28.8 \%$ were repeating the current course due to a previous course withdrawal or unsatisfactory grade.

The courses sampled for the present study were part of the instructional sequence required by students majoring in biology and were usually taken during the first two years of college. The students enrolled in these course usually have a wide variety of academic and career goals. Many of these students have defined goals, such as medical, dental or veterinary graduate programs, upon graduation and therefore have higher ACT scores than the general population. Other students take these courses in order to fulfill general education requirements. This group of students may have variable ACT scores and choose to defer their biology course until their final semester.

\subsection{Materials}

A recent evaluation of classroom and laboratory practices in the Department of Biology at this public university found that classroom practices and some laboratories needed significant 
updating to meet the learning goals of its students, to increase student retention, and to reduce costs to students. Toward this end, the Biology Department negotiated a contract with McGraw Hill to provide multiple digital materials, including common e-texts, at an economical price for students enrolled in 100-level and 200-level biology courses. The general biology classes were lecture sections of General Biology for non-majors, Biological Concepts I: Cells, Metabolism and Genetics, Biological Concepts II: Ecology and Evolution, Human Anatomy and Physiology (A\&P) I, Advanced Human Anatomy and Physiology, and General Microbiology. The general biology courses $(N=895)$ adopted the McGraw-Hill LearnSmart and Smartbook adaptive learning tools, further identified as the general biology group of this study. The A\&P laboratory courses $(N=439)$ adopted McGraw-Hill E-text and Connect learning environments, subsequently labeled the lab group.

The e-text materials used in each group offered distinctly different learning experiences. The general biology lecture courses' e-texts were "Smartbooks" that used LearnSmart which included embedded questioning and interactive modules that assessed student reading comprehension and tailored the book content to individual student needs. Highlighted segments of the Smartbook changed from yellow to green as a student mastered content as measured by the questions in the Learnsmart software (Figure 2). Students who mastered content more quickly were given fewer questions than students who guessed or did not understand the material. Metacognition data were collected measuring how confident a student was about his/her answers to questions. 


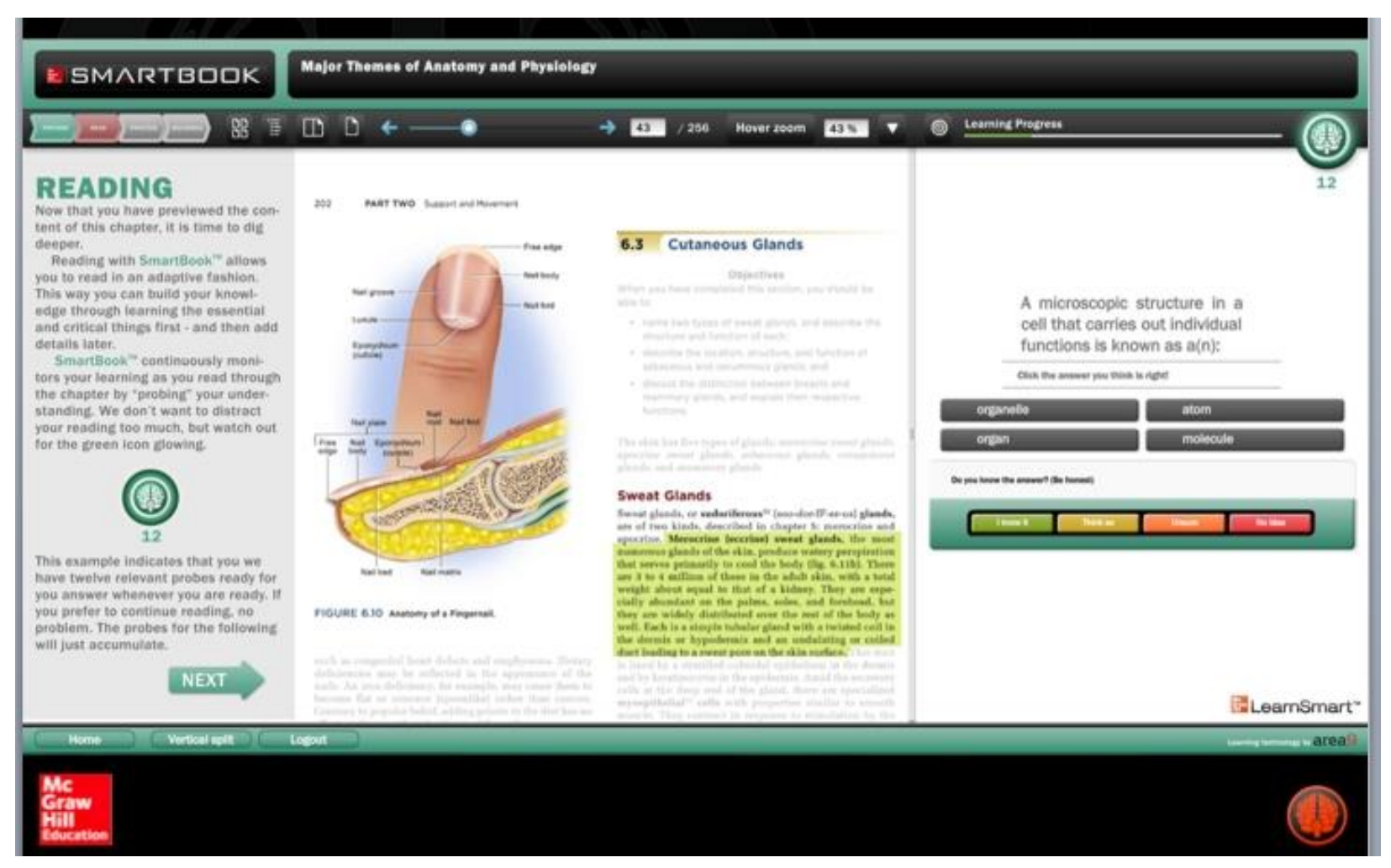

Figure 2. A screenshot of LearnSmart and Smartbook interactive learning modules

The A\&P lab courses used an e-text as well, but they were not Smartbooks. Instead of using the adaptive Learnsmart system, students were assigned homework within the Connect platform that was not adaptive. Specific question sets were selected for the lab exercises to help students master lab content. Often this content emphasized skill and drill learning activities to reinforce student factual knowledge of human anatomy and physiology (Figure 3). 



Figure 3. Sample screenshots of McGraw-Hill E-text and Connect learning environments

\subsection{Procedure}

Students completed a series of anonymous online questionnaires that were administered near the end of spring semester (May) of 2015 after students had worked with the e-texts during the whole semester. A link to an online survey was embedded within the learning management system (LMS) for each course section of the general biology and anatomy and physiology courses. Students were provided with an informed consent document at the beginning of the online survey that outlined the purpose of the study, the voluntary nature of the study, the anticipated benefits and potential risks, and steps that were being taken by the research team to protect the confidentiality of the data collected. The consent process also outlined steps to link Institutional/University records/data with individual survey responses. The institutional data included student's college admissions test (ACT) scores, age, academic year, number of completed hours, and current undergraduate Grade Point Average (GPA).

All procedures performed in studies involving human participants were in accordance with the ethical standards of the institutional and/or national research committee and with the 1964 Helsinki declaration and its later amendments or comparable ethical standards. 


\subsection{Measures}

Student motivation associated with a self-directed use of e-text materials was assessed using a simplified version of Keller's (1993, 2010) Instructional Material Motivation Survey (IMMS) that was designed in correspondence with Keller's ARCS theory of motivation (Keller, 1987a, 1987b). The IMMS instrument included 16 Likert-type items that measured four motivational dimensions of the ARCS model: attention, relevance, confidence, and satisfaction (ARCS). Each ARCS dimension was assessed using four items with response choices of 1 (not true), 2 (slightly true), 3 (moderately true), 4, (mostly true), and 5 (very true). The ARCS scores were calculated by averaging the four items on each sub-scale respectively. The IMMS instrument and its four sub-scales had a moderately high level of internal consistency (Table 1) as measured using a Cronbach's alpha test. The IMMS instrument's validity was empirically established in several previous studies with a large number of participants (e.g., Huang, Huang, Diefes-Dux, \& Imbrie, 2006; Loorbach, Peters, Karreman, \& Steehouder, 2015).

Table 1

Cronbach's Alpha Test of Reliability for Dimensions of ARCS Model

\begin{tabular}{lll}
\hline & $\begin{array}{c}\text { General Biology } \\
(N=456)\end{array}$ & $\begin{array}{c}\text { A\&P Lab Courses } \\
(N=271)\end{array}$ \\
\hline Attention & .791 & .791 \\
Relevance & .614 & .682 \\
Confidence & .748 & .765 \\
Satisfaction & .793 & .817 \\
Intrinsic Cognitive Load & .869 & .892 \\
Extraneous Cognitive Load & .840 & .867 \\
Frustration & .895 & .905 \\
\hline
\end{tabular}


Intrinsic and extraneous cognitive load (IL and EL) measurements associated with using e-texts were assessed using a nine-item questionnaire (Authors, 2018). The e-text cognitive load questionnaire used in the current study was adapted from the questionnaire developed by Leppink et al. (2013) to measure cognitive load for a lecture/paper-based mode of learning. The item response choices ranged from 0 (not true at all) to 10 (completely the case). The first four items included statements intended to capture e-text IL, such as "the topics covered in the e-text were very complex" and "I invested a very high mental effort in the complexity of the e-text content." The last five items measured e-text EL and included items such as "Manipulating etexts (e.g., highlighting, bookmarking, navigating, searching information) was very distracting" and "Reading e-texts off a screen was, in terms of learning, very ineffective." The intrinsic and extraneous cognitive load scales exhibited high reliabilities (Table 1). The e-text cognitive load instrument was empirically validated with a large sample of 1377 undergraduate students (Authors, 2018).

Frustration with e-text technical issues and lack of instructional alignment were measured using eleven 7-point Likert scale questions. Eight of these questions evaluated students' experiences with e-text technical issues and three additional questions evaluated perceived lack of instructional alignment between e-text materials and course goals and requirements. The questions were developed based on previous research that showed that error messages, poor network connections, long download time, and hard-to-find features were among the most-cited reasons for frustrating experiences with computers (Ceaparu et al., 2004; Selvidge, Chaparro, \& Bender, 2002). In addition, prior research on challenges associated with using e-texts (i.e., e-text 
navigation, bookmarking, highlighting, lack of physical structure like in printed materials, reading off a screen) was used to develop items measuring student frustration with using e-texts.

Questions that assessed frustrating experiences with the lack of instructional alignment were developed based on the expectancy-value theories that assume that individual willingness to engage in a particular effort depends on the perceived importance of that effort (Wigfield \& Eccles, 2000). A clear connection between the e-text learning materials and course requirements is believed to promote student motivation and persistence to learn (Keller, 2008a). If students can clearly see how e-text assignments and activities can help achieve course expectations, they will be more willing to use the e-texts resulting in higher perceived value. Overall, the frustration questionnaire had a high level of internal consistency (Table 1).

\subsection{Data Analysis}

A series of hierarchical multiple regression analyses were computed to analyze the relationships among motivational processing variables (ARC components), cognitive load (information processing), frustration with e-texts, and academic ability variables. The motivational processing variables were previously explored in Huang et al.'s (2010) and Author's (2014) studies and, therefore, were entered into the model first. Additional predictor variables were entered in the following order: (1) ACT math scores and academic hours completed, (2) intrinsic and extraneous cognitive load, and (3) frustration using e-texts. The order of entering these additional predictors was determined based on their theoretical importance and prior research that examined similar variables as predictors of human performance or attitudes (Field, 2013). Based on past research, student distal variables (longstanding academic characteristics) were found to be effective predictors of student success, and 
therefore ACT math scores and academic hours completed variables were entered into the model after the motivational processing variables (ARC components). Proximal variables (closer to the time of data collection in the present study), e.g., information processing and frustration with etexts variables, were entered afterward.

In line with the MVP theory that views student satisfaction as a learning outcome or the product of the learner's mental evaluation of her/his achievement, student satisfaction, as measured by the ARCS satisfaction subscale (Keller, 1993), was the dependent variable.

\section{Results}

The means and standard deviations for the outcome and predictor variables in general biology and A\&P lab courses are presented in Table 2.

Table 2 Means and SDs of Predictors and Criterion Variables in General Biology and A\&P Lab Courses

\begin{tabular}{lcccc}
\hline \multirow{2}{*}{ Variable } & General Biology $(\boldsymbol{N}=\mathbf{4 5 6})$ & \multicolumn{2}{c}{ A\&P Lab courses $(\boldsymbol{N}=\mathbf{2 7 1})$} \\
\cline { 2 - 5 } Satisfaction & $\boldsymbol{M}$ & $\boldsymbol{S D}$ & $\boldsymbol{M}$ & $\boldsymbol{S D}$ \\
Attention & 3.22 & .98 & 3.14 & 1.01 \\
Relevance & 2.85 & .93 & 2.89 & .84 \\
Confidence & 3.35 & .79 & 3.25 & .82 \\
ACT Math & 3.35 & .86 & 3.25 & .85 \\
Academic Hours Completed & 22.94 & 4.83 & 22.13 & 4.44 \\
Intrinsic CL & 54.93 & 28.49 & 59.11 & 31.76 \\
Extraneous CL & 5.12 & 1.96 & 5.23 & 1.99 \\
Frustration & 3.97 & 2.28 & 4.20 & 2.45 \\
Note. Possible score range for Attention, Relevance, Confidence, Satisfaction scales and Computer Skills: 1-5. Possible score range for Intrinsic \\
and Extraneous CL: 0-10. ACT math scores range from 1-36, with 36 being the highest possible score.
\end{tabular}

A correlation matrix of all of the study variables is presented in Table 3 for the six general biology courses and in Table 4 for the A\&P Lab Courses. 
Table 3

Correlation matrix: General biology courses

\begin{tabular}{lccccccccc}
\hline Variable & \multicolumn{1}{c}{1} & \multicolumn{1}{c}{2} & 3 & 4 & 5 & 6 & 7 & 8 & 9 \\
\hline 1. Satisfaction & 1.00 & & & & & & & & \\
2. Attention & $.79^{* *}$ & 1.00 & & & & & & & \\
3. Relevance & $.75^{* *}$ & $.71^{* *}$ & 1.00 & & & & & & \\
4. Confidence & $.76^{* *}$ & $.66^{* *}$ & $.67^{* *}$ & 1.00 & & & & & \\
5. ACT math & $-.10^{*}$ & $.10^{*}$ & .002 & .06 & 1.00 & & & & \\
6. Academic Hours & -.04 & .001 & -.04 & $.08^{*}$ & $.18^{* *}$ & 1.00 & & & \\
Completed & & & & & & & & & \\
7. Intrinsic CL & .06 & $.08^{*}$ & $.09^{*}$ & $-.11^{*}$ & $-.13^{* *}$ & $-.11^{* *}$ & 1.00 & & \\
8. Extraneous CL & $-.38^{* *}$ & $-.22^{* *}$ & $-.23^{* *}$ & $-.36^{* *}$ & -.08 & .03 & $.45^{* *}$ & 1.00 & \\
9. Frustration & $-.53^{* *}$ & $-.44^{* *}$ & $-.41^{* *}$ & $-.48^{* *}$ & -.07 & .05 & $.18^{* *}$ & $.57^{* *}$ & 1.00 \\
\hline
\end{tabular}

**. Correlation is significant at the 0.01 level (2-tailed).

*. Correlation is significant at the 0.05 level (2-tailed).

Table 4

Correlation matrix: A\&P lab courses

\begin{tabular}{llllllllll}
\hline Variable & \multicolumn{1}{c}{1} & \multicolumn{1}{c}{2} & \multicolumn{1}{c}{3} & 4 & 5 & 6 & 7 & 8 & 9 \\
\hline 1. Satisfaction & 1.00 & & & & & & & & \\
2. Attention & $.78^{* *}$ & 1.00 & & & & & & & \\
3. Relevance & $.79^{* *}$ & $.73^{* *}$ & 1.00 & & & & & & \\
4. Confidence & $.81^{* *}$ & $.67^{* *}$ & $.74^{* *}$ & 1.00 & & & & & \\
5. ACT math & -.02 & .06 & .08 & $.16^{* *}$ & 1.00 & & & & \\
6. Academic Hours & -.06 & .04 & -.01 & .07 & $.24^{* *}$ & 1.00 & & & \\
Completed & & & & & & & & & \\
7. Intrinsic CL & .07 & .09 & .10 & -.08 & $-.18^{* *}$ & $-.18^{* *}$ & 1.00 & & \\
8. Extraneous CL & $-.39^{* *}$ & $-.28^{* *}$ & $-.28^{* *}$ & $-.39^{* *}$ & $-.15^{* *}$ & -.06 & $.53^{* *}$ & 1.00 & \\
9. Frustration & $-.45^{* *}$ & $-.37^{* *}$ & $-.34^{* *}$ & $-.48^{* *}$ & $-.18^{* *}$ & -.07 & $.33^{* *}$ & $.64^{* *}$ & 1.00 \\
\hline
\end{tabular}

**. Correlation is significant at the 0.01 level (2-tailed)

Table 5 illustrates the prediction for student satisfaction across the two learning conditions. Using a hierarchical multiple regression analysis, attention, relevance, confidence, intrinsic and extraneous cognitive load, ACT math scores, and academic hours completed were found to be significant predictors of student satisfaction in both learning conditions. Student frustration with e-text was a significant predictor in the general biology lecture condition, but not 
in the A\&P lab. Since the motivational processing variables (ARC components) were identified in previous research as significant predictors of student satisfaction (Huang et al., 2010; Author, 2014), these variables were entered into the model's first block of the hierarchical regression. The first multiple regression model explained $73 \%$ of the variation in the students' satisfaction in the general biology condition and in the A\&P lab courses. Similar to Huang et al.'s (2010) and Author's (2014) studies, attention, relevance, and confidence had significant predicting power.

Student ability variables (prior knowledge as measured by ACT math score and previous academic background as measured by academic hours completed) were entered into the second model. The predictor variables on Model 2 explained $75 \%$ of the variation in the students' satisfaction in the general biology condition and $76 \%$ in the A\&P lab courses. Both prior knowledge and academic background variables were significant negative predictors of student etext satisfaction.

Including IL and EL variables (Model 3) significantly increased the adjusted $R^{2}$ value to .77 in the general biology and A\&P conditions. IL had a positive significant influence while EL had significant negative effect on e-text satisfaction.

Model 4 accounted for the contributions of motivational processing variables, student ability variables, information processing, and e-text frustration. Including e-text frustration resulted in a significant model in both learning conditions, explaining $78 \%$ of the variation in the students' satisfaction in the general biology condition and $77 \%$ in the A\&P lab courses.

However, the incremental increase in $\mathrm{R}^{2}$ was not significant in the A\&P lab courses. In addition, e-text frustration was a significant negative predictor in the general biology condition only (Table 5). 
Table 5

Multiple Regression Models Predicting Students' Satisfaction in General Biology and A\&P Lab Courses

\begin{tabular}{|c|c|c|c|c|c|c|c|c|}
\hline \multirow[b]{3}{*}{ Variable } & \multicolumn{4}{|c|}{ General Biology Courses $(N=456)$} & \multicolumn{4}{|c|}{ A\&P Lab courses $(N=271)$} \\
\hline & \multicolumn{2}{|c|}{ Unstandardized } & \multicolumn{2}{|c|}{$\begin{array}{l}\text { Standar } \\
\text { dized }\end{array}$} & \multicolumn{2}{|c|}{ Unstandardized } & \multicolumn{2}{|c|}{$\begin{array}{l}\text { Standar } \\
\text { dized }\end{array}$} \\
\hline & Beta & SE Beta & $\boldsymbol{\beta}$ & $T$ & Beta & SE Beta & $\beta$ & $T$ \\
\hline \multicolumn{9}{|l|}{ Model 1} \\
\hline Constant & -.29 & .11 & & $-2.65^{* *}$ & -.51 & .14 & & $-3.69 * *$ \\
\hline Attention & .44 & .04 & .41 & $12.00 * * *$ & .36 & .06 & .30 & $6.63 * * *$ \\
\hline Relevance & .31 & .05 & .25 & $7.04 * * *$ & .30 & .06 & .24 & $5.03 * * *$ \\
\hline Confidence & .36 & .04 & .32 & $9.72 * * *$ & .51 & .06 & .43 & $9.32 * * *$ \\
\hline \multicolumn{9}{|l|}{ Model 2} \\
\hline Constant & .17 & 1.53 & & 1.13 & .13 & .19 & & .70 \\
\hline Attention & .42 & .04 & .40 & $11.74 * * *$ & .35 & .05 & .29 & $6.65^{* * *}$ \\
\hline Relevance & .30 & .04 & .24 & $6.89 * * *$ & .29 & .06 & .24 & $5.14 * * *$ \\
\hline Confidence & .39 & .04 & .34 & $10.58 * * *$ & .55 & .05 & .46 & $10.39 * * *$ \\
\hline $\begin{array}{l}\text { ACT } \\
\text { Academic }\end{array}$ & -.02 & .01 & -.07 & $-2.99 * *$ & -.03 & .01 & -.11 & $-3.58 * * *$ \\
\hline $\begin{array}{l}\text { Hours } \\
\text { Completed }\end{array}$ & -.002 & .001 & -.08 & $-3.18 * *$ & -.003 & .001 & -.08 & $-2.65 * *$ \\
\hline \multicolumn{9}{|l|}{ Model 3} \\
\hline Constant & .44 & .17 & & $2.59 *$ & 2.54 & .23 & & 1.09 \\
\hline Attention & .40 & .03 & .38 & $11.56^{* * *}$ & .33 & .05 & .27 & $6.38 * * *$ \\
\hline Relevance & .27 & .04 & .21 & $6.33 * * *$ & .25 & .06 & .20 & $4.48 * * *$ \\
\hline Confidence & .36 & .04 & .32 & $9.89 * * *$ & .53 & .05 & .45 & $9.74 * * *$ \\
\hline $\mathrm{ACT}$ & -.02 & .01 & -.07 & $-3.16 * *$ & -.03 & .01 & -.11 & $-3.51 * *$ \\
\hline Academic & & & & & -.002 & .001 & -.06 & $-2.09 *$ \\
\hline Hours & -.002 & .001 & -.05 & $-2.21 *$ & & & & \\
\hline Completed & & & & & & & & \\
\hline Intrinsic CL & .07 & .01 & .12 & $4.73 * * *$ & .07 & .02 & .14 & $3.78 * * *$ \\
\hline Extraneous CL & -.08 & .01 & -.19 & $-7.22 * * *$ & -.07 & .02 & -.16 & $-4.33 * * *$ \\
\hline \multicolumn{9}{|l|}{ Model 4} \\
\hline Constant & .65 & .19 & & $3.36^{* *}$ & .36 & .27 & & 1.34 \\
\hline Attention & .38 & .04 & .36 & $11.08 * * *$ & .32 & .05 & .27 & $6.29 * * *$ \\
\hline Relevance & .26 & .04 & .21 & $6.24 * * *$ & .24 & .06 & .20 & $4.39 * * *$ \\
\hline Confidence & .35 & .04 & .30 & $9.45 * * *$ & .52 & .06 & .44 & $9.44 * * *$ \\
\hline ACT & -.02 & .01 & -.08 & $-3.35^{* *}$ & -.03 & .01 & -.11 & $-3.55 * * *$ \\
\hline Academic & & & & & -.002 & .001 & -.07 & $-2.14^{*}$ \\
\hline Hours & -.002 & .001 & -.05 & $-2.05^{*}$ & & & & \\
\hline Completed & & & & & & & & \\
\hline Intrinsic CL & .06 & .01 & .12 & $4.81 * * *$ & .07 & .02 & .14 & $3.83 * * *$ \\
\hline Extraneous CL & -.07 & .01 & -.16 & $-5.08 * * *$ & -.06 & .02 & -.15 & $-3.45^{* *}$ \\
\hline Frustration & -.05 & .02 & -.07 & $-2.23^{*}$ & -.02 & .03 & -.03 & -.78 \\
\hline
\end{tabular}

Note. $* \rho<.05, * * \rho<.01, * * * \rho<.001$

General biology:

Model 1: $R^{2}=.74$, adjusted $R^{2}=.73, F(3,452)=418.08, \rho<.001$;

Model 2: $\Delta R^{2}=.01$, adjusted $R^{2}=.75, F(2,450)=11.48, \rho<.001$;

Model 3: $\Delta R^{2}=.03$, adjusted $R^{2}=.77, F(2,448)=27.98, \rho<.001$;

Model 4: $\Delta R^{2}=.002$, adjusted $R^{2}=.77, F(1,447)=4.95, \rho<.05$. 
A\&P Lab courses:

Model 1: $R^{2}=.74$, adjusted $R^{2}=.73, F(3,267)=249.66, \rho<.001$;

Model 2: $\Delta R^{2}=.02$, adjusted $R^{2}=.76, F(2,265)=13.01, \rho<.001$;

Model 3: $\Delta R^{2}=.02$, adjusted $R^{2}=.77, F(2,263)=11.27, \rho<.001$;

Model 4: $\Delta R^{2}=.001$, adjusted $R^{2}=.77, F(1,262)=.61, \rho>.05$.

\section{Discussion}

The study revealed significant relationships among motivational, information processing, student academic background and prior knowledge variables, and student satisfaction with e-text learning in two different learning conditions, a set of general biology courses as well as anatomy and physiology (A\&P) lab courses. Student interest toward e-texts (attention), clear connection between student goals and e-texts (relevance), expectancy for success with e-texts (confidence), intrinsic and extraneous cognitive load, academic background and prior knowledge were significant and consistent predictors of e-text satisfaction in the general biology and A\&P lab learning conditions.

In line with previous research, student motivational variables had the strongest predicting power on the outcome processing variable (Huang et al., 2010); Author, 2014). Student ability, information processing, and frustration variables have not been examined in previous research on MVP mathematical modeling. The current study revealed that information processing had the second highest predicting power. Student ability levels had a very small yet significant (negative) effect. Student frustration with using e-text was a significant negative predictor of student satisfaction in the general biology condition only, thus somewhat limiting the generalizability of this variable in the MVP mathematical model. Given the significance of the model that predicted students' satisfaction based on the variables that were consistent significant predictors in both learning conditions, it is possible to present the following mathematical MVP model: 
Satisfaction $(\mathrm{s})=\mathrm{A} \times$ Attention $(\mathrm{s})+\mathrm{B} \times$ Relevance $(\mathrm{s})+\mathrm{C} \times$ Confidence $(\mathrm{s})+\mathrm{D} \times \mathrm{IL}(\mathrm{s})+\mathrm{E} \times$

$$
\text { EL(s) }+\mathrm{F} \times \text { Academic_Background(s) }+\mathrm{G} \times \text { Prior_Knowledge(s) }
$$

(A, B, C, and D are positive parameters; E, F, and $\mathrm{G}$ are negative parameters; $\mathrm{s}=$ student).

A closer examination of the mathematical MVP model predictors in the general biology courses and A\&P lab courses revealed that attention and confidence had the highest (positive) predicting power on student satisfaction in both learning conditions. However, the magnitude of these variables was different in the two conditions, reflecting the differences in these two distinct learning environments. Attention was the strongest predictor of student satisfaction in the general biology condition $\left(\beta_{\text {Lecture }}=.36\right.$ vs. $\left.\beta_{\text {Lab }}=.27\right)$ while confidence was the strongest predictor in the $\mathrm{A} \& \mathrm{P}$ lab condition $\left(\beta_{\text {Lecture }}=.30\right.$ vs. $\left.\beta_{\text {Lab }}=.44\right)$. Interestingly, these findings reflect the actual differences in two e-text learning environments. The general biology lecture courses aimed to promote an understanding of biological concepts and interrelationships among them. The e-text selected for these courses mirrored the course objectives. They employed adaptive learning tools that offered various self-assessments and consequently responded to the students' academic needs by directing their attention to specific sections in the e-text and additional learning resources, such as multimedia presentations, videos, and tutorials, when they experienced confusion. In keeping with expectations, the novelty of these e-text materials and their interactivity is reflected in students' increased interest toward e-text materials, which was captured by the attention variable.

The A\&P lab courses had completely different learning targets. A major goal was to build student factual knowledge of human anatomy and physiology. Students had hands-on 
experience with lab materials, such as bones and models, and needed the e-text and assignments to provide practice with learning the names of structures outside of scheduled time in the lab. Their e-text materials emphasized skill and drill learning activities, helping students memorize structures illustrated in their e-texts, which consequently resulted in higher confidence.

The rest of the mathematical MVP model predictors appeared to have similar predicting power in the general biology and A\&P lab courses. The e-text relevance to course objectives and expectations was the third strongest (positive) predictor of student satisfaction with the e-texts $\left(\beta_{\text {Lecture }}=.21\right.$ vs. $\left.\beta_{\text {Lab }}=.20\right)$. This positive relationship is consistent with the goal orientation and self-determination theories (Deci \& Ryan, 1985) that highlight the importance of engaging in activities that match learners' interests and preferences.

The IL variable had a smaller (positive) effect $\left(\beta_{\text {General_Biology }}=.12\right.$ vs. $\left.\beta_{\text {A\&P_Lab }}=.14\right)$, suggesting that both learning environments used e-texts that were compatible with student academic needs and prior knowledge. According to cognitive load theory, IL captures mental effort associated with processing of new information (Sweller, 2010; Van Merriënboer \& Sweller, 2005). It is influenced by student prior knowledge and learning task difficulty. Therefore, optimal learning materials can enhance learning and result in higher satisfaction with the learning processes, as suggested by the MVP mathematical model. It is important to note that student prior knowledge and academic background were entered into the hierarchical regression prior to the IL variable. This research design allowed for the control of student prior knowledge when examining the relationships among the outcome processing variable and IL, and the model determined that IL was a positive, significant predictor of student outcome processing even after controlling for the effects of motivation and prior knowledge. 
The EL variable had the strongest negative predicting power $\left(\beta_{\text {General_Biology }}=-.16 \mathrm{vs}\right.$. $\left.\beta_{A \& P_{-} L a b}=-.15\right)$. EL involves the additional load beyond the IL that is necessary to process new information. It may be attributed to the factors that activate additional cognitive processes that are extraneous to the learning process and do not contribute to better learning, such as poorly designed learning materials, reading off a screen, and manipulating (navigating, bookmarking, searching, etc.) e-texts (Authors, 2018). Consistent with cognitive load theory, our MVP mathematical model revealed that EL had a negative effect on student satisfaction with the e-text learning.

Student general ability variables (academic background and prior knowledge) had the smallest effect. It appears that students who had lower prior knowledge and/or fewer academic hours reported higher satisfaction levels than students with higher prior knowledge and/or more advanced academic background. One of the possible explanations for these findings could be that e-texts provided extra learning resources and scaffolding that were particularly beneficial for students with lower ability levels. Students with higher ability levels possibly did not need these extra resources and therefore perceived them less helpful. In any case, the student ability variables had almost negligent (negative) yet significant predicting power on student e-text satisfaction.

\section{Practical Implications}

In addition to research implications discussed above, the MVP mathematical model can be used as a tool for diagnosing and remediating students' learning experiences as well as analyzing learning materials and environments. Table 6 summarizes the elements that received empirical support in the MVP mathematical model. The motivational variables positively 
correlated with student satisfaction, suggesting that (1) in order to increase student satisfaction with e-text learning it is important to select e-texts of high-quality design and align them with course objectives (attention and relevance) and that (2) preparing students for e-text learning can increase their confidence and result in higher satisfaction (confidence). The quality of welldesigned e-text materials is crucial when implementing e-text learning. It directly influences students' satisfaction and motivates continuous use of e-text materials (Piccoli et al. 2001; Sun et al., 2008). In addition to selecting high quality e-texts, it is imperative to prepare students for etext learning. The importance of students' e-learning readiness has received a considerable attention from the research community. Researchers argue that a successful completion of elearning course materials is critical for students' satisfaction with the learning process and academic success, since it serves as a prerequisite for completing other course requirements (Hao, 2016; Hung, Chou, Chen, \& Own, 2010; Yilmaz, 2017). According to Hung et al. (2010), students' e-learning readiness includes five dimensions: self-directed learning, motivation for learning, computer/Internet self-efficacy, learner control, and online communication selfefficacy. When implementing e-text learning, instructors should consider students' readiness across these five dimensions. For instance, it would be beneficial to assess students' e-learning readiness before introducing students to e-texts. Based on the assessment results, instructors can decide which aspects of e-learning readiness need to be enhanced and what is the best way of doing it. Research on e-textbook learning provides similar recommendations arguing that many students do not know how to use e-textbooks effectively and need to be taught how to do it (Thomas, 2013). 
Table 6

A Summary of Practical Implications for Learning with E-Texts.

\begin{tabular}{lll}
\hline Predictor & Indicator of & Implications \\
\hline Attention & Interest toward e-text learning & E-text design, novelty, and appeal \\
Relevance & $\begin{array}{l}\text { Connection between goals and } \\
\text { interests, and e-text learning and } \\
\text { motivational processes }\end{array}$ & $\begin{array}{l}\text { Clear alignment between course } \\
\text { objectives and e-text materials }\end{array}$ \\
Confidence & Expectancy for success with e-texts & $\begin{array}{l}\text { Prepare students for learning with e- } \\
\text { texts }\end{array}$ \\
$\begin{array}{l}\text { Intrinsic CL } \\
\text { Extraneous CL }\end{array}$ & $\begin{array}{l}\text { Processes that do not contribute to or } \\
\text { hamper knowledge construction }\end{array}$ & $\begin{array}{l}\text { E-textbook usability } \\
\text { Use of optimal learning materials }\end{array}$ \\
$\begin{array}{l}\text { Academic } \\
\text { Background } \\
\text { Prior } \\
\text { Knowledge }\end{array}$ & Student ability variables & $\begin{array}{l}\text { E-textbooks can be particularly } \\
\text { recommended for new and low- } \\
\text { performing students }\end{array}$ \\
\hline
\end{tabular}

In addition to motivational variables, the MVP mathematical model provided empirical support for the information processing variables, i.e., intrinsic and extraneous cognitive load. Intrinsic cognitive load was positively correlated with student satisfaction, suggesting that providing students with optimal learning materials increases their satisfaction with the learning process. Extraneous cognitive load (e.g., reading off a screen, navigating, scrolling, bookmarking, and searching e-text materials) was negatively correlated with student satisfaction. This finding is in line with prior research demonstrating that factors associated with extraneous cognitive load can negatively affect student satisfaction (Leppink et al., 2014; Sweller \& Chandler, 1994). This negative correlation suggests the importance of selecting e-text materials that are intuitive and easy to use. It is worth mentioning that in spite of the growing e-textbook adoption rates in K-12 and higher education settings, students do not strongly prefer e-texts over 
printed textbooks (Authors, 2018; Shepperd et al., 2008; Woody et al., 2010). Among the possible reasons are factors contributing to e-text extraneous cognitive load, such as navigating, scrolling, bookmarking, and searching e-texts (Authors, 2018). As such, in order to increase students' satisfaction with e-text learning it is important to evaluate both the content and usability/perceived ease of use of e-texts with the targeted learning audience.

Finally, student academic background and prior knowledge variables were significant negative predictors of e-text satisfaction, indicating that e-texts can be particularly beneficial for sustaining a continuous desire to learn among new and low-performing students. Overall, the practical implications suggested by the mathematical MVP model have been extensively acknowledged in the professional educational literature, which provides further support for the elements included in the mathematical MVP model and model's applicability to various learning environments.

\section{Generalizability of a Mathematical MVP Model}

A mathematical MVP model developed in the present study describes relationships among various motivational, cognitive, and environmental variables that affect student e-text learning experiences. The model (Equation 2) performed well in two distinct e-text learning settings providing support for its generalizability. Examining how well a mathematical MVP model performs across a broader range of learning environments can provide further empirical support for the elements that are included in the model. If a model can accurately predict the same outcome variable from the same set of predictor variables in a different sample, then its level of generalizability increases. Although the amount of research on MVP mathematical modeling is extremely limited, two additional studies used a MVP mathematical model to examine student learning (Huang et al., 2010; Author, 2014). Huang et al. (2010) applied 
Keller's (2008b) MVP theory to examine game-based learning and Author (2014) studied student performance in a simulation-based learning environment. A comparison of MVP model indicators across the four distinct learning environments (Table 7) suggests that a mathematical MVP model performed reasonably well within each learning environment, producing consistent trends and findings. In particular, it revealed that motivation processing variables had the highest predictive power in explaining the student outcome processing variable in all four learning conditions. Moreover, its predictive power, as measured by $R^{2}$, has increased considerably from .43 in Huang and colleagues' (2010) study to .77 in the present study, clearly indicating that applying a model with additional predictor variables to different groups of people results in an increased predictive power, and therefore, the model generalizes across different learning environments and populations.

Table 7

Summary Statistics of MVP Mathematical Model Indicators by Learning Setting

\begin{tabular}{lllll}
\hline Predictor & $\begin{array}{l}\text { General Biology } \\
\text { E-text } \\
(N=456)\end{array}$ & $\begin{array}{l}\text { A\&P Lab } \\
\text { E-text } \\
(N=271)\end{array}$ & $\begin{array}{l}\text { Author (2014) } \\
\text { Simulation } \\
(N=62)\end{array}$ & $\begin{array}{l}\text { Huang et al. (2010) } \\
\text { Video Game } \\
(N=264)\end{array}$ \\
\hline Attention & $B=.36$ & $\beta=.27$ & $\beta=.51$ & $\beta=.32$ \\
Relevance & $\beta=.21$ & $\beta=.20$ & $\beta=.37$ & $\beta=.37$ \\
Confidence & $\beta=.30$ & $\beta=.44$ & $\beta=.19$ & $\beta=.19$ \\
Intrinsic CL & $\beta=.12$ & $\beta=.14$ & N/A & N/A \\
Extraneous CL & $\beta=-.16$ & $\beta=-.15$ & N/A & N/A \\
Academic Background & $\beta=-.05$ & $\beta=-.07$ & N/A & N/A \\
Prior knowledge & $\beta=-.08$ & $\beta=-.11$ & N/A & N/A \\
Volition & N/A & N/A & $\beta=.17$ & N/A \\
Frustration & $\beta=-.07$ & Non-sig & N/A & N/A \\
& & & & \\
\hline
\end{tabular}




\begin{tabular}{lllll}
\hline Total $\mathrm{R}^{2}$ & .77 & .77 & .69 & .43
\end{tabular}

Note. N/A means that a variable was not examined

A review of the aforementioned studies that developed and evaluated MVP mathematical models highlights the challenges associated with mathematical modeling in educational and more generally in social and behavioral research - data availability and need for replication studies. An MVP mathematical model includes many variables, which are often difficult to obtain for a given set of study participants and replicate in different learning settings. For instance, the initial intent of the present study was to include an indicator of student volition (e.g., effort persitance), which could be measured by e-text homework scores or/and e-text learning time. These data were only available through the e-text publishing company, which limited our ability to test the volition component in a mathematical MVP model. This lack of consistency in data sets poses considerable research challenges and requires development and application of appropriate methodological data analysis approaches (Dabbaghian \& Mago, 2014) as well as additional research that attempts to replicate existing mathematical models in different learning environments with different populations and additional variables. 


\section{References}

Author (2014)

Authors (2018)

Ackerman, R., \& Lauterman, T. (2012). Taking reading comprehension exams on screen or on paper? A metacognitive analysis of learning texts under time pressure. Computers in Human Behavior, 28, 1816-1828.

Adams, J. S. (1965). Inequity in social exchange. In L. Berkowitz (Ed.), Advances in experimental social psychology (Vol. 2). New York:Academic Press.

Anderson, A. K. (2014). Use of admissions data to predict student success in postsecondary freshman science. (PhD Dissertation), Capella University.

Apple, I. (2015). Not just reading - Interacting: The textbook transformation. Retrieved from https://www.apple.com/education/ipad/ibooks-textbooks/

Atkinson, R. C., \& Schiffrin, R. M. (1971). The control of short-term memory. Scientific American, 225, 82-90.

Biermann, C. A., \& Sarinsky, G. B. (1989). Selected factors associated with achievement of biology preparatory students and their follow-up to higher level biology courses. Journal of Research in Science Teaching, 26(7), 575-586.

Boroughs, D. (2010). Bye the book: In educational publishing the only certainty is change. PRISM 19. Retrieved from http://www.prism-magazine.org/apr10/feature_01.cfm

Ceaparu, I., Lazar, J., Bessiere, K., Robinson, J., \& Shneiderman, B. (2004). Determining Causes and Severity of End-User Frustration. International Journal of Human-Computer Interaction, 17(3), 333-356. 
Dabbaghian, V., \& Mago, V. K. (2014). Theories and Simulations of Complex Social Systems. Berlin Heidelberg: Springer.

Deci, E. L., \& Ryan, R. (1985). Intrinsic motivation and self-determination in human behavior. New York: Plenum.

Deng, L., Turner, D.E., Gehling, R. , \& Prince, B. (2010). User experience, satisfaction, and continual usage intention of IT. European Journal of Information Systems, 19 (1), 60-75.

Dennis, A. (2011). e-Textbooks at Indiana University: A summary of two years of research. Indiana University. Bloomington, IN.

Festinger, L. (1957). A Theory of Cognitive Dissonance. Stanford, CA: Stanford University Press.

Fletcher, G., Schaffhauser, D., \& Levin, D. (2012). Out of print: Reimagining the K-12 textbook in a digital age. Paper presented at the State Educational Technology Directors Association (SETDA), Washington, DC.

Gollwitzer, P. M. (1999). Implementation Intentions. Strong effects of simple plans. American Psychologist, 54(7), 493-503.

Hao, Y. (2016). Exploring undergraduates' perspectives and flipped learning readiness in their flipped classrooms. Computers in Human Behavior, 59, 82-92.

Heider, R. (1958). The psychology of interpersonal relations. New York: Wiley.

Huang, W., Huang, W., Diefes-Dux, H., \& Imbrie, P. K. (2006). A preliminary validation of Attention, Relevance, Confidence and Satisfaction model-based Instructional Material Motivational Survey in a computer-based tutorial setting. British Journal of Educational Technology, 37(2), 243-259. 
Huang, W.-H., Huang, W.-Y., \& Tschopp, J. (2010). Sustaining iterative game playing processes in DGBL: The relationship between motivational processing and outcome processing. Computers \& Education, 55(2), 789-797.

Hummon, N. P., \& Doreian, P. (2003). Some dynamics of social balance processes: bringing Heider back into balance theory. Social Networks, 25(1), 17-49.

Hung, M. L., Chou, C., Chen, C. H., \& Own, Z. Y. (2010). Learner readiness for online learning: Scale development and student perceptions. Computers \& Education, 55(3), 1080-1090.

Hyman, J. A., Moser, M. T., \& Segala, L. N. (2014). Electronic reading and digital library technologies: Understanding learner expectation and usage intent for mobile learning. Educational Technology Research and Development, 63, 35-52.

Kang, Y.S., \& Lee, H. (2010). Understanding the role of an IT artifact in online service continuance: An extended perspective of user satisfaction, Computers in Human Behavior, 26 (3), 353-364.

Keller, J. M. (1987a). Development and use of the ARCS model of motivational design. Journal of Instructional Development, 10(3), 2-10.

Keller, J. M. (1987b). Strategies for stimulating the motivation to learn. Performance and Instruction, 26(8), 1-7.

Keller, J. M. (1993). Motivation by design. Florida State University. Tallahassee, Florida.

Keller, J. M. (1999). Using the ARCS motivational process in computer-based instruction and distance education. New Directions for Teaching and Learning, 78, 39-48.

Keller, J. M. (2008a). First principles of motivation to learn and e3-learning. Distance Education, 29(2), 175-185. 
Keller, J. M. (2008b). An integrative theory of motivation, volition, and performance. Technology, Instruction, Cognition and Learning, 16, 79-104.

Keller, J. M. (2010). Motivational Design for Learning and Performance: The ARCS Model Approach. New York: Springer.

Kuhl, J. (1987). Action control: The maintenance of motivational states. In F. Halisch \& J. Kuhl (Eds.), Motivation, Intention and Volition (pp. 279-291). Berlin: Springer.

Lamb, A. (2001). Reading redefined for a transmedia universe. Learning \& Leading with Technology, 39(3), 12-17.

Le Bigot, L., \& Rouet, J. F. (2007). The impact of presentation format, task assignment, and prior knowledge on students' comprehension of multiple online documents. Journal of Literacy Research, 39(4), 445-470.

Leppink, J., Paas, F., Van der Vleuten, C. P. M., Van Gog, T., \& Van Merriënboer, J. J. G. (2013). Development of an instrument for measuring different types of cognitive load. Behavior Research Methods, 45(4), 1058-1072.

Leppink, J., Paas, F., van Gog, T., van der Vleuten, C. P. M., \& van Merriënboer, J. J. G. (2014). Effects of pairs of problems and examples on task performance and different types of cognitive load. Learning and Instruction, 30, 32-42.

Liu, Z. (2005). Reading behavior in the digital environment: Changes in reading behavior over the past ten years. Journal of Documentation, 61(6), 700-712.

Loorbach, N., Peters, O., Karreman, J., \& Steehouder, M. (2015). Validation of the Instructional Materials Motivation Survey (IMMS) in a self-directed instructional setting aimed at working with technology. British Journal of Educational Technology, 46(1), 204-218.

Mayer, R. E. (2001). Multimedia Learning. Cambridge: Cambridge University Press. 
Oliver, R.L. (1977). Effect of expectation and disconfirmation on postexposure product evaluations: An alternative interpretation. Journal of Applied Psychology, 62(4), 480486.

Oliver, R.L. (1980). A cognitive model of the antecedents and consequences of satisfaction decisions. Journal of Marketing Research, 17(4), 460-469.

Paas, F., Renkl, A., \& Sweller, J. (2003). Cognitive load theory and instructional design: Recent developments. Educational Psychologist, 38(1), 1-4.

Pearl, J. (2000). Causality: Models, reasoning, and inference. Cambridge, England: Cambridge University Press.

Pfaffl, M. W. (2001). A new mathematical model for relative quantification in real-time RTPCR. Nucleic acids research, 29(9), e45-e45.

Piccoli, G., Ahmad, R., \& Ives, B. (2001). Web-based virtual learning environments: a research framework and a preliminary assessment of effectiveness in basic IT skill training. MIS Quarterly, 25(4), 401-426.

Rockinson- Szapkiw, A. J., Courduff, J., Carter, K., \& Bennett, D. (2013). Electronic versus traditional print textbooks: A comparison study on the influence of university students' learning. Computers \& Education, 63, 259-266.

Rodgers, J. L. (2010). The epistemology of mathematical and statistical modeling: A quiet methodological revolution. American Psychologist, 65(1), 1-12.

Selvidge, P. R., Chaparro, B. S., \& Bender, G. T. (2002). The world wide wait: Effects of delays on user performance. International Journal of Industrial Ergonomics, 29, 15-20.

Shepperd, J. A., Grace, J. L., \& Koch, E. J. (2008). Evaluating the electronic textbook: is it time to dispense with the paper text? Teaching of Psychology, 35, 2-5. 
Sun, P.-C., Tsai, R. J., Finger, G., Chen, Y.-Y., \& Yeh, D. (2008). What drives a successful eLearning? An empirical investigation of the critical factors influencing learner satisfaction. Computers \& Education, 50(4), 1183-1202.

Sweller, J. (2010). Element interactivity and intrinsic, extraneous and germane cognitive load. Educational Psychology Review, 22, 123-138.

Sweller, J., \& Chandler, P. (1994). Why some material is difficult to learn. Cognition and Instruction, 12, 185-223.

Tamura, K., Masatoshi, N., \& Sudhir, K. (2004). Prospects for inferring very large phylogenies by using the neighbor-joining method. Paper presented at the Proceedings of the National Academy of Sciences of the United States of America

Thomas, A. (2013). A study of algebra 1 students' use of digital and print textbooks. (PhD Dissertation), University of Missouri-Columbia.

Van Merriënboer, J. J. G., \& Sweller, J. (2005). Cognitive load theory and complex learning: Recent developments and future directions. Educational Psychology Review, 17, 147177.

Weisberg, M. (2011). Student attitudes and behaviors towards digital textbooks. Publishing Research Quarterly, 27(2), 188-196.

Wigfield, A., \& Eccles, J. S. (2000). Expectancy-value theory of achievement motivation. Contemporary Educational Psychology, 25(1), 68-81.

Woody, W. D., Daniel, D. B., \& Baker, C. A. (2010). E-books or textbooks: students prefer textbooks. Computers \& Education, 55, 945-948.

Zimmerman, B. J. (2001). Theories of self-regulated learning and academic achievement: An overview and analysis. In B. J. Zimmerman \& D. H. Schunk (Eds.), Self-Regulated 
Learning and Academic Achievement. Theoretical Perspectives (pp. 1-38). Erlbaum, NJ:

Mahwah. 